Article

\title{
Synthesis and Characterization of New Benzo[e]Indol Salts for Second-Order Nonlinear Optics
}

\author{
Jiahui Wen ${ }^{1,2}$, Linjun Ping ${ }^{2}$, Ruian $\mathrm{Li}^{3}$, Shufang Shang ${ }^{2}$, Weidong Zhao ${ }^{2}$, Mingtan Hai ${ }^{2}$, \\ Hui Cao ${ }^{2, *}$, Xiaotao Yuan ${ }^{1, *}$, Dong Wang ${ }^{2}$, Wanli $\mathrm{He}^{2}$ and Zhou Yang ${ }^{2, *}$ \\ 1 School of Chemistry \& Biological Engineering, University of Science and Technology Beijing, Beijing 100083, \\ China; wwwenjh@gmail.com \\ 2 School of Materials Science and Engineering, University of Science and Technology Beijing, Beijing 100083, \\ China; pinglinjun@163.com (L.P.); G20178345@xs.ustb.edu.cn (S.S.); b20170237@xs.ustb.edu.cn (W.Z.); \\ mingtanhai@mater.ustb.edu.cn (M.H.); wangdong@mater.ustb.edu.cn (D.W.); \\ hewanli@mater.ustb.edu.cn (W.H.) \\ 3 Beijing Key Laboratory of Energy Conversion and Storage Materials, College of Chemistry, Beijing Normal \\ University, Beijing 100875, China; ruian000123@hotmail.com \\ * Correspondence: caohui@mater.edu.cn (H.C.); yuanxt@ustb.edu.cn (X.Y.); yangz@ustb.edu.cn (Z.Y.)
}

Received: 24 February 2020; Accepted: 25 March 2020; Published: 26 March 2020

\begin{abstract}
Organic second-order nonlinear optical materials are of great significance in the field of integrated photonics, optical data storage and optical information processing. In this work, two iodide salts with benzo[e]indol cations as electron-withdrawing groups were designed and synthesized, which are (E)-2-(4-hydroxy-3-methoxystyryl)-1,1,3-trimethyl-1H-benzo[e]indol-3-ium iodide (1-TB) and (E)-2-(3,4-dihydroxystyryl)-1,1,3-trimethyl-1H-benzo[e]indol-3-ium iodide (2-TB). Under the irradiation of $1064 \mathrm{~nm}$ laser, the second harmonic generations of the 1-TB and 2-TB powders are 760 and 580 times that of urea, respectively. Among them, crystals of 1-TB are successfully grown by a slow cooling method without using seed crystals. Bulk crystal with a size of $8.0 \times 3.0 \times 1.0 \mathrm{~mm}^{3}$ and many submillimeter single crystals with excellent optical quality are obtained.
\end{abstract}

Keywords: organic single crystal; nonlinear optical materials

\section{Introduction}

With the development of the information age, optoelectronic technology has gradually become the main pillar of information technology in the 21st century [1-8]. In nonlinear optical (NLO) materials, organic NLO materials have better molecular plasticity, faster optical response rate, larger NLO performance than inorganic NLO materials, and have been rapidly developed [9]. The most notable of current organic NLO materials are DAST (N,N-dimethyla-mino-N'-methyl-stilbazolium p-toluenesulfonate) [10] and DSTMS (4-N,N-dimethylamino-4'-N'-methyl-stilbazolium 2,4,6-trimethylbenzenesulfonate) [11]. They have been proven to be good terahertz emitters and detectors with much higher electric field peak signal and correspondingly cut-off frequencies than the inorganic crystals ZnTe and GaAs [12-15]. In recent years, other organic crystals with large second harmonic generations (SHG) have been reported: OH1 (2-(3-(4-hydroxystyryl)-5,5-dimethylcyclohex-2-enylidene)malononitrile) crystals show high terahertz generation at the wavelength range of 1200 to $1460 \mathrm{~nm}[14,16,17]$; $\mathrm{OHQ}$ (2-(4-hydroxystyryl)-1-methylquinolinium benzenesulfonate) exhibits superior second-order nonlinear optical efficiency in the near-infrared wavelength range of 800 to $1200 \mathrm{~nm}[18,19]$; HMQ (2-(4-hydroxy-3-methoxystyryl)-1-methylquinolinium benzenesulfonate) and HMB (2-(4-hydroxy-3-methoxystyryl)-3-methylbenzo[d]thiazol-3-ium) series single crystals have the same order of magnitude of nonlinear optical susceptibilities as DAST and DSTMS [20-22]. 
Although DAST and DSTMS have a very high SHG, the actual nonlinear coefficient is only one tenth of the theoretical calculation result [23]. At the same time, organic single crystals require complicated growth conditions and long growth cycles, which greatly limits the application of organic second-order NLO materials. There is an urgent need to research second-order NLO materials with high SHG properties and good crystal growth abilities.

To obtain an organic single crystal that satisfies the strong macroscopic second-order nonlinear optical characteristics of laser frequency conversion and terahertz wave generation, the preparation of a large first-order hyperpolarizabilities $\beta$ of chromophore is the primary premise. In most of the conjugated organic molecules, the first-order hyperpolarizabilities are dominated by intramolecular charge transfers. This paper reports two iodonium salts using benzo[e]indol as an electron-accepting group. The molecular formulas of 1-TB and 2-TB are shown in Scheme 1. The $\mathrm{R}$ substituent of $1-\mathrm{TB}$ is a methoxy group compared to the hydroxyl group of 2-TB. The synthesis of 1-TB has been published but without involving research in the field of nonlinear optics [24], while 2-TB is an organic second-order nonlinear optical salt material that has not yet been published yet. The 1-TB and 2-TB are designed as D- $\pi$-A delocalized systems with benzo[e]indol cation as the electron-withdrawing group and pair-arranged (hydroxy, methoxy) combination to provide electrons [25]. It is well-known that a necessary requirement for the generation of second-order nonlinearity is the noncentrosymmetric arrangement of the chromophore molecules. However, statistics show that $75 \%$ of organic materials cannot express macroscopic second-order nonlinearity due to centrosymmetric arrangement of crystals [3]. Thus, it is important to develop new organic single crystals that have higher NLO properties.

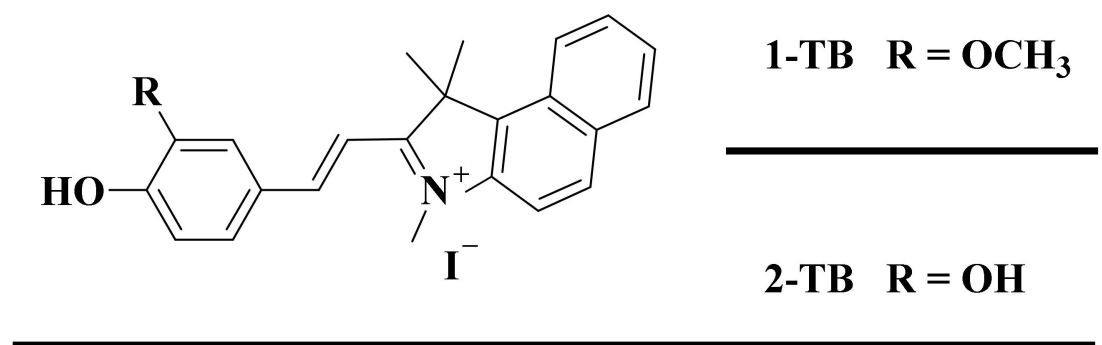

Scheme 1. Molecular structure of 1-TB and 2-TB.

Here, the SHG signals of the 1-TB and 2-TB powders are 760 and 580 times that of urea, indicating that both the 1-TB and 2-TB crystals are noncentrosymmetric crystals. On the one hand, the crystal structure in the electron-withdrawing group containing benzene ring structures, which makes the electron transfer more favorable. On the other hand, the benzo[e]indol salt gives greater asymmetry to the chromophore compared to methylbenzene and quinoline due to its larger group structure [26]. It has been experimentally confirmed that 1-TB can be directly grown (without seeding) to quickly obtain organic single crystals. The 1-TB crystal structure indicates that the anion forms an $\mathrm{O}-\mathrm{H} \ldots$ I hydrogen bond with the hydroxyl group, and the $\mathrm{O}-\mathrm{H} \ldots$... I hydrogen bond can reduce the energy of the whole system and keep it more stable [27-29]. These advancements indicate that the 1-TB is an organic second-order NLO salt material with promising applications.

\section{Experimental Section}

\subsection{Materials and Instruments}

All reagents and medicines were purchased from J\&K Scientific Ltd. (Beijing, China) and used without treatment. ${ }^{1} \mathrm{H}$ NMR spectra of 1-TB and, 2-TB were recorded on a Bruker $500 \mathrm{MHz}$ spectrometer (Bruker, Billerica, MA, USA) in Dimethyl Sulfoxide (DMSO) solutions. Elemental analyses were performed by Element Analyzer (Vario EL III, elementar Analysensysteme GmbH, Langenselbold, Germany) in Tsinghua University. UV-vis spectra were recorded by a UV-vis spectrophotometer 
(JASCOV-570, Tokyo, Japan). Thermal analyses were conducted on a PerkinElmer Pyris 6 DSC (Differential scanning calorimetry) spectrometer (PerkinElmer Inc., Waltham, MA, USA) at a heating rate of $10^{\circ} \mathrm{C} \cdot \mathrm{min}^{-1}$ under a dry nitrogen purge. Diffraction intensities for 1-TB single-crystal at $100 \mathrm{~K}$ were collected on an Oxford Gemini S Ultra Charge Coupled Device (CCD) diffractometer (UK) with graphite monochromated Mo-K $\alpha$ radiation $(\lambda=0.71073 \AA)$ [28]. THz generation was measured using TeraScan (TOPTICA) with $100 \mathrm{fs}$ laser pump pulses at a wavelength $\lambda=780 \mathrm{~nm}$.

\subsection{Synthesis of 1,1,2,3-Tetramethyl-1H-Benzo[e]indol-3-Ium-Iodide}

Firstly, $9.12 \mathrm{~g}$ of 1,1,2-trimethyl- $1 \mathrm{H}$-benzo[e]indol and $2.0 \mathrm{~mL}$ of methyl iodide were dissolved in $120 \mathrm{~mL}$ of methanol, refluxed at $75^{\circ} \mathrm{C}$ and stirred. It is worth to note that $1.5 \mathrm{~mL}$ of methyl iodide was added every $90 \mathrm{~min}$ due to its high volatility. The reaction was complete after $8 \mathrm{~h}$ of tracking with a dot plate to produce a pale-yellow precipitate with a yield of $87 \%$. Then, it was recrystallized with methanol as solvent, completely dissolved and cooled, precipitated, filtered and dried to prepare for the next reaction.

${ }^{1} \mathrm{HNMR}(500 \mathrm{MHz}, \mathrm{DMSO}): 8.25 \sim 8.27\left(\mathrm{~d}, 1 \mathrm{H}, \mathrm{C}_{10} \mathrm{H}_{6}\right), 8.04 \sim 8.11\left(\mathrm{~m}, 2 \mathrm{H}, \mathrm{C}_{10} \mathrm{H}_{6}\right), 7.77 \sim 7.79(\mathrm{~d}, 1 \mathrm{H}$, $\left.\mathrm{C}_{10} \mathrm{H}_{6}\right), 7.66 \sim 7.69\left(\mathrm{~m}, 1 \mathrm{H}, \mathrm{C}_{10} \mathrm{H}_{6}\right), 7.51 \sim 7.54\left(\mathrm{~m}, 1 \mathrm{H}, \mathrm{C}_{10} \mathrm{H}_{6}\right), 3.79\left(\mathrm{~s}, 3 \mathrm{H}, \mathrm{CH}_{3}\right), 2.61\left(\mathrm{~s}, 3 \mathrm{H}, \mathrm{CH}_{3}\right), 1.93(\mathrm{~s}$, $\left.6 \mathrm{H}, \mathrm{CH}_{3}\right) \mathrm{ppm}$. MS, m/z: $224.3(\mathrm{M}+)$.

\subsection{Synthesis of $1-T B$}

3,4-dihydroxybenzaldehyde (5.0 g) and 1,1,2,3-tetramethyl-1 $H$-benzo[e]indol iodide ( $8.4 \mathrm{~g})$ (the molar ratio between the two are 1.1:1) was added to in $120 \mathrm{~mL}$ of anhydrous methanol and 5 to 6 drops of piperidine were added dropwise as a catalyst. After the reaction was completely over, the reflux reaction was subsequently performed for $24 \mathrm{~h}$ under the conditions of $80^{\circ} \mathrm{C}$. Afterwards, the reaction mixture was cooled to room temperature and most of the solvent was removed by rotary evaporation. The resulting product was recrystallized three times using methanol as a solvent and the solid was filtered and dried under vacuum for $72 \mathrm{~h}$. A red solid was finally obtained.

${ }^{1} \mathrm{H}$ NMR $\left(500 \mathrm{MHz}\right.$, DMSO- $\left.d_{6}\right): 10.49(\mathrm{~s}, 1 \mathrm{H}), 8.39 \sim 8.47(\mathrm{~m}, 2 \mathrm{H}), 8.28(\mathrm{~d}, J=8.9 \mathrm{~Hz}, 1 \mathrm{H}), 8.21(\mathrm{~d}$, $J=8.3 \mathrm{~Hz}, 1 \mathrm{H}), 8.07(\mathrm{~d}, J=8.9 \mathrm{~Hz}, 1 \mathrm{H}), 7.75 \sim 7.84(\mathrm{~m}, 3 \mathrm{H}), 7.71(\mathrm{t}, J=7.5 \mathrm{~Hz}, 1 \mathrm{H}), 7.50(\mathrm{~d}, J=16.2 \mathrm{~Hz}$, 1H), $6.98(\mathrm{~d}, J=8.2 \mathrm{~Hz}, 1 \mathrm{H}), 4.23(\mathrm{~s}, 3 \mathrm{H}), 3.94(\mathrm{~s}, 3 \mathrm{H}), 2.01(\mathrm{~s}, 6 \mathrm{H}) \mathrm{ppm}$. MS, m/z: $358.5(\mathrm{M}+)$. Elemental Analysis: Calcd (\%) for C24H24INO2: C, 59.38; H, 4.98; N, 2.89; found: C, 59.19; H, 5.16; N, 2.84 .

\subsection{Synthesis of $2-T B$}

2-hydroxy-4-methoxybenzaldehyde (5.0 g) and 1,1,2,3-tetramethyl-1H-benzo[e]indol iodide (8.5 g) (the molar ratio between them is 1.1:1) were added to in $120 \mathrm{~mL}$ of anhydrous methanol and 5 to 6 drops of piperidine were added dropwise as a catalyst. The spotting plate was traced until the reaction materials are completely reacted and the reflux reaction for $24 \mathrm{~h}$ under the conditions of $80^{\circ} \mathrm{C}$. Afterwards, the reaction mixture is cooled to room temperature and most of the solvent was removed by rotary evaporation. The resulting product was recrystallized three times using methanol as a solvent and the solid was filtered and dried under vacuum for $72 \mathrm{~h}$. A brown solid was finally obtained.

${ }^{1} \mathrm{H}$ NMR $\left(500 \mathrm{MHz}\right.$, DMSO- $\left.d_{6}\right): 10.57(\mathrm{~s}, 1 \mathrm{H}), 9.38(\mathrm{~s}, 1 \mathrm{H}), 8.33 \sim 8.43(\mathrm{~m}, 2 \mathrm{H}), 8.27(\mathrm{~d}, J=8.9 \mathrm{~Hz}$, $1 \mathrm{H}), 8.20(\mathrm{~d}, J=8.2 \mathrm{~Hz}, 1 \mathrm{H}), 8.06(\mathrm{~d}, J=8.9 \mathrm{~Hz}, 1 \mathrm{H}), 7.76 \sim 7.83(\mathrm{~m}, 1 \mathrm{H}), 7.70(\mathrm{t}, J=7.5 \mathrm{~Hz}, 1 \mathrm{H}), 7.59 \sim 7.67$ $(\mathrm{m}, 2 \mathrm{H}), 7.40(\mathrm{~d}, J=16.2 \mathrm{~Hz}, 1 \mathrm{H}), 6.95(\mathrm{~d}, J=8.2 \mathrm{~Hz}, 1 \mathrm{H}), 4.20(\mathrm{~s}, 3 \mathrm{H}), 1.99(\mathrm{~s}, 6 \mathrm{H}) \mathrm{ppm}$. MS, m/z: 344.5 $(\mathrm{M}+)$. Elemental Analysis: Calcd (\%) for C23H22INO2: C,58.60; H,4.70; N, 2.97; found: $\mathrm{C}, 58.48 ; \mathrm{H}$, $4.87 ; \mathrm{N}, 3.06$.

\section{Results and Discussion}

\subsection{Environmental Stability and Solubility}

We performed differential scanning calorimetry, thermal gravimetric analysis (see Supplementary Materials Figure S1), UV-vis spectroscopy, and solubility tests on the 1-TB and 2-TB. The melting point, 
maximum UV-vis absorption wavelength, and the solubility contrast between pure solvent methanol and mixed solvents (methanol: acetonitrile $=1: 1 \mathrm{vol} / \mathrm{vol}$ ) were obtained. The specific data is shown in Table 1.

Table 1. Physical properties of investigated compounds.

\begin{tabular}{|c|c|c|c|c|c|c|}
\hline Samples & $\begin{array}{c}\lambda_{\max }{ }^{a} \\
(\mathrm{~nm})\end{array}$ & $\begin{array}{c}\text { Melting } \\
\text { Point } \\
\left({ }^{\circ} \mathrm{C}\right)\end{array}$ & $\begin{array}{c}\text { Molecular-Ordering } \\
\text { Angle }\end{array}$ & $\begin{array}{c}\text { Order } \\
\text { Parameter } \cos ^{3} \\
(\theta p)\end{array}$ & $\begin{array}{l}\text { Crystal Structure } \\
\text { (Point Group) }\end{array}$ & $\begin{array}{l}\text { Powder } \\
\text { SHG }^{\text {b }}\end{array}$ \\
\hline 1-TB & 574 & 268 & 50 & 0.26 & Monclinic $\mathrm{P} 2{ }_{1}$ & 0.76 \\
\hline $2-\mathrm{TB}$ & 574 & 265 & - & - & - & 0.58 \\
\hline DAST & 475 & 256 & 20 & 0.83 & Monclinic Cc & 1 \\
\hline DSTMS & 475 & 258 & 23 & 0.75 & Monclinic Cc & 1 \\
\hline P-BI-1 & 550 & 263 & 45 & 0.35 & Monclinic $\mathrm{P} 2_{1}$ & 1.14 \\
\hline
\end{tabular}

From Table 1, it can be seen that the 1-TB and 2-TB have higher thermal stability than DAST with a melting point of $257^{\circ} \mathrm{C}$. Their melting points are $268^{\circ} \mathrm{C}$ and $265^{\circ} \mathrm{C}$, respectively. Moreover, the 1-TB and 2-TB decomposition temperature exceeded $250^{\circ} \mathrm{C}$. The thermal stability of 1-TB and 2-TB is critical because it furnishes a wider range of applications for laser frequency conversion and terahertz wave detection. In addition, the solubilities of 1-TB and 2-TB in water are extremely poor and the hydrated central symmetric phase does not form even if crystallized in an aqueous solvent.

Both the 1-TB and 2-TB UV-vis absorption spectra are obtained by dissolving them in methanol. UV-vis absorption spectra indicate that 1-TB and 2-TB have the maximum absorption peak at $574 \mathrm{~nm}$ in methanol (Figure 1). The absorption intensities of 1-TB and 2-TB in methanol are similar with that of DAST at $532 \mathrm{~nm}$. The nonlinear optical materials of the benzo[e]indol series exhibit a significant red shift of $98 \mathrm{~nm}$ with respect to the well-known DAST, which is mainly related to the electron acceptor of benzo[e]indol cation. Also related to the electron donating group in the cation correlation of methoxy and phenol, which can be seen by comparing P-BI ((E)-2-(4-(dimethylamino)styryl)-1,1,3-trimethyl-1H-benzo[e]indol-3-ium iodide) [30], was a red shift of $22 \mathrm{~nm}$. Therefore, we have more reasons to expect this series of benzo[e]indol iodides to have good macroscopic second-order nonlinear properties.

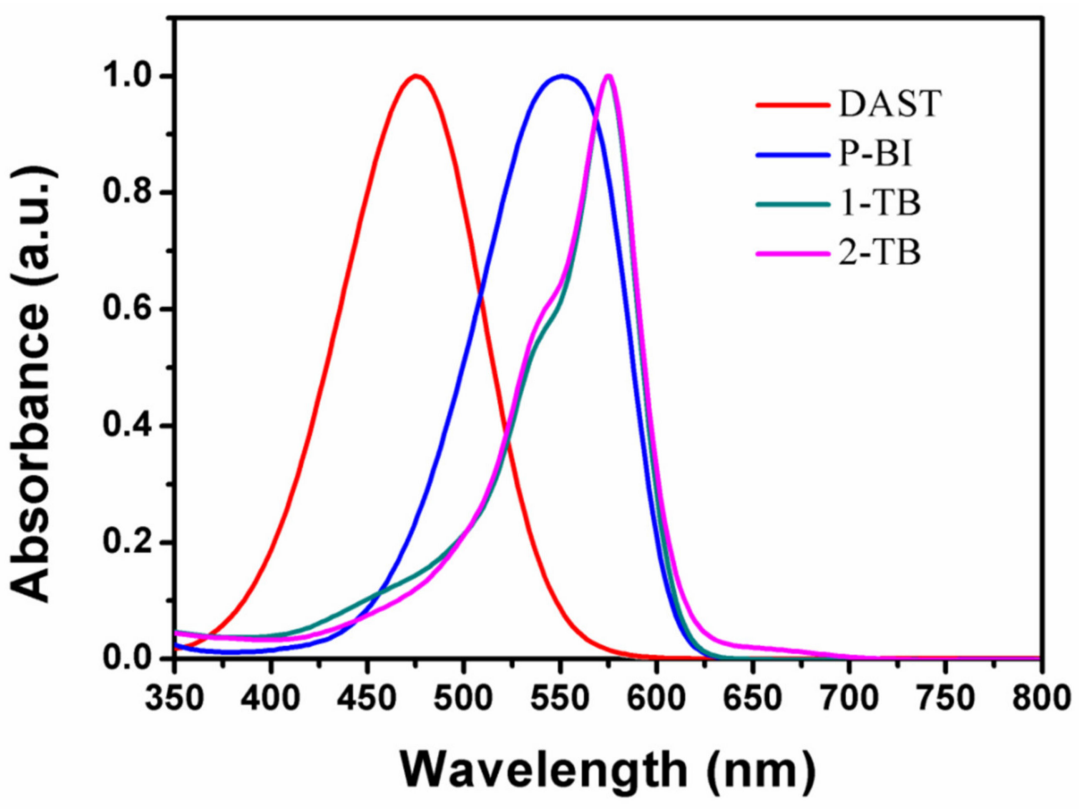

Figure 1. Absorption spectra of DAST, P-BI, 1-TB and 2-TB in methanol. 


\subsection{Single Crystal Growth and Characterization}

The salts synthesized can be well dissolved in methanol/acetonitrile (1:1 vol/vol), while they show poor solubility in other organic solvents such as dichloromethane, acetonitrile and acetone, etc. Thus, methanol/acetonitrile $(1: 1 \mathrm{vol} / \mathrm{vol})$ was selected to grow crystals of 1-TB and 2-TB. Firstly, the excess of the benzo[e]indol iodide salt dissolved in $100 \mathrm{~g}$ methanol/acetonitrile $(1: 1 \mathrm{vol} / \mathrm{vol})$ in an oil bath and was heated to $50^{\circ} \mathrm{C}$ for $6 \mathrm{~h}$ to fully dissolve. Next, the solution was filtered while remaining hot, and the solution was transferred to a clean Erlenmeyer flask using a $0.22-\mu \mathrm{m}$ filter. Then, the solubility at this temperature was calculated. The solubility at $60^{\circ} \mathrm{C}, 40^{\circ} \mathrm{C}, 30^{\circ} \mathrm{C}$, and $20^{\circ} \mathrm{C}$ can be calculated separately as described above.

From the solubility diagram Figure 2, it can be seen that the 1-TB solubility in methanol/acetonitrile $(1: 1 \mathrm{vol} / \mathrm{vol})$ is much higher than that in pure methanol. Due to the fact that $1-\mathrm{TB}$ has a solubility difference of $0.60 \mathrm{~g} / 100 \mathrm{~g}$ solvent in the range of $30{ }^{\circ} \mathrm{C}$ to $50{ }^{\circ} \mathrm{C}$, the slow-cooling method can be used to grow 1-TB crystals. According to the solubility test results, the near-saturated solution in methanol/acetonitrile $(1: 1 \mathrm{vol} / \mathrm{vol})$ is first configured at $50{ }^{\circ} \mathrm{C} .1 .70 \mathrm{~g}$ of $1-\mathrm{TB}$ was placed in $100 \mathrm{~g}$ of the above-mentioned mixed solvent and stirred well for $12 \mathrm{~h}$ until completely dissolved. After a period of stabilization, the temperature was gradually decreased at a rate of $2{ }^{\circ} \mathrm{C} / \mathrm{d}$. And after dropping to $38^{\circ} \mathrm{C}$, it was declined at a rate of $1^{\circ} \mathrm{C} / \mathrm{d}$. Finally, a green rectangular prism with a size of $8.0 \times 3.0 \times 1.0 \mathrm{~mm}^{3}$ and several high-quality crystals were obtained (Figure $3 a, b)$. The growth cycle is about two weeks.

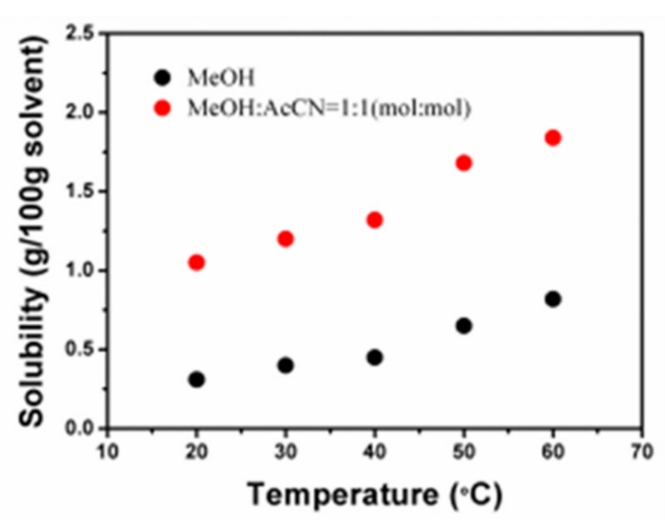

(a)

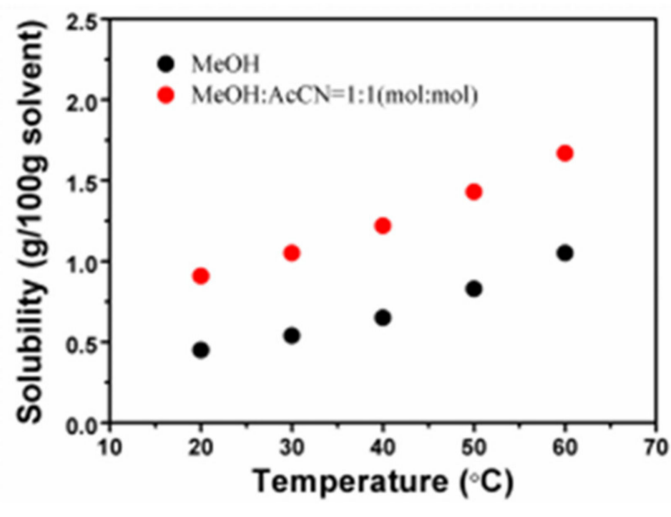

(b)

Figure 2. Solubility of the 1-TB and 2-TB in pure methanol (a) and methanol/acetonitrile (1:1 vol/vol) (b) at different temperatures.

Experiments under the same conditions show that the solubility of 2-TB is lower than that of 1-TB, and its crystallinity is not ideal. We decided to slowly evaporate the solvent at room temperature, which is the most suitable crystal growth method for the 2-TB. In this work, we select three high solubility solvents to grow 2-TB crystals by slow evaporation. Among them, DMSO has high solubility. However, it is not suitable for growing crystals due to its slow evaporation rate and long growth cycle. On the contrary, the solubility in acetonitrile is the highest, but its volatilization rate is very fast so that it is easy to form crystalline clusters. The solubility and volatility in methanol are moderate. In terms of comprehensive solubility and volatility, we found that it is a relatively suitable method to grow 2-TB single crystals in methanol/acetonitrile (1:1 vol/vol).

The submillimeter 1-TB single crystal has very good permeability under the nonorthogonal condition of the polarizing microscope and has few crystal defects. Figure $3 c, d$ shows the image of the crystal (Figure 3b) alternates between light and dark whenever it is rotated $45^{\circ}$ around the direction of polarizing light propagation, indicating the obtained crystal is a single crystal. Uniform extinction between crossed polarizer indicates that the crystal has good optical quality. The appropriate size can be directly used for the detection of terahertz waves and other related applications. These can 
prove that the 1-TB single crystal with good optical quality is obtained: the surface is smooth and the thickness is uniform.

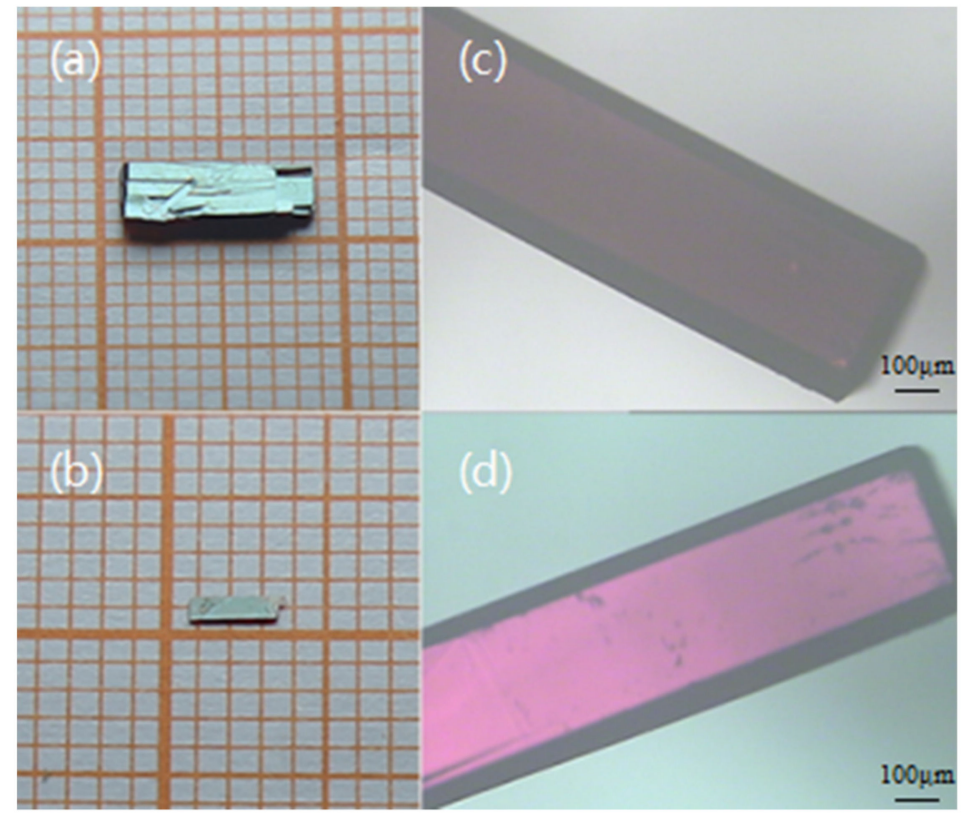

Figure 3. 1-TB single crystals grown in methanol/acetonitrile (1:1 vol/vol) $(\mathbf{a}, \mathbf{b}), 1-\mathrm{TB}$ (b) dark field in the case of orthogonal polarized light (c), and reaching maximum transmittance after rotating $45^{\circ}(\mathbf{d})$.

\subsection{Macroscopic Second-Order Nonlinear Optical Properties}

The introduction of benzo[e]indol cation can optimize the molecular structure, and the interaction between molecules can be inhibited. In addition, the strong acceptor groups provided by such molecules with long conjugated structures make it easier for high density electron clouds at the donor end to migrate in the conjugated molecules, thus it is possible to obtain a larger first-order hyperpolarizabilities $\beta$. The second harmonic intensities of the 1-TB and 2-TB crystal powders irradiated by the 1064-nm laser were 0.76 and 0.58 times of the DAST (Table 2), respectively, showing good macroscopic second-order nonlinear optical properties [30-32].

Table 2. Second-order nonlinear intensity at $1064 \mathrm{~nm}$ for powders of the DAST, 1-TB, and 2-TB.

\begin{tabular}{cc}
\hline Sample & SHG Intensity (a.u.) \\
\hline DAST & 1 \\
$1-T B$ & 0.76 \\
$2-T B$ & 0.58 \\
\hline
\end{tabular}

The Bond Length Alternation Theory proposed by Seth R. Marder et al. in the 1990s has a theoretical guiding significance for the introduction of benzo[e]indol cations [28]. The first-order hyperpolarizability $\beta$ of the chromophore will increase as the BLA value decreases. Benzo[e]indol cations help reduce the BLA value, and increase the first-order hyperpolarizabilities $\beta$ of the chromophore.

$$
B L A=\frac{\left[\left(\mathrm{s}_{1}-d_{1}\right)+\left(\mathrm{s}_{2}-d_{2}\right)+\left(\mathrm{s}_{3}-d_{3}\right)\right]}{3}
$$

As shown in the Figure 4, the bond lengths from left to right in the blue dashed box are $1.425 \AA$, $1.430 \AA, 1.453 \AA, 1.353 \AA, 1.409 \AA$, and $1.386 \AA$, respectively. The differences between the delocalized single and double bonds are $\Delta \mathrm{r}=0.005 \AA, 0.10 \AA, 0.023 \AA$, and the crystal structure data of 1 -TB verify that the benzo[e]indol acceptor cation can enhance intramolecular charge transfer by adjusting the relative 
length. The bond length between alternating single and double bonds is very short, and the value of BLA also becomes smaller, which is favorable for obtaining larger first-order hyperpolarizabilities $\beta$.

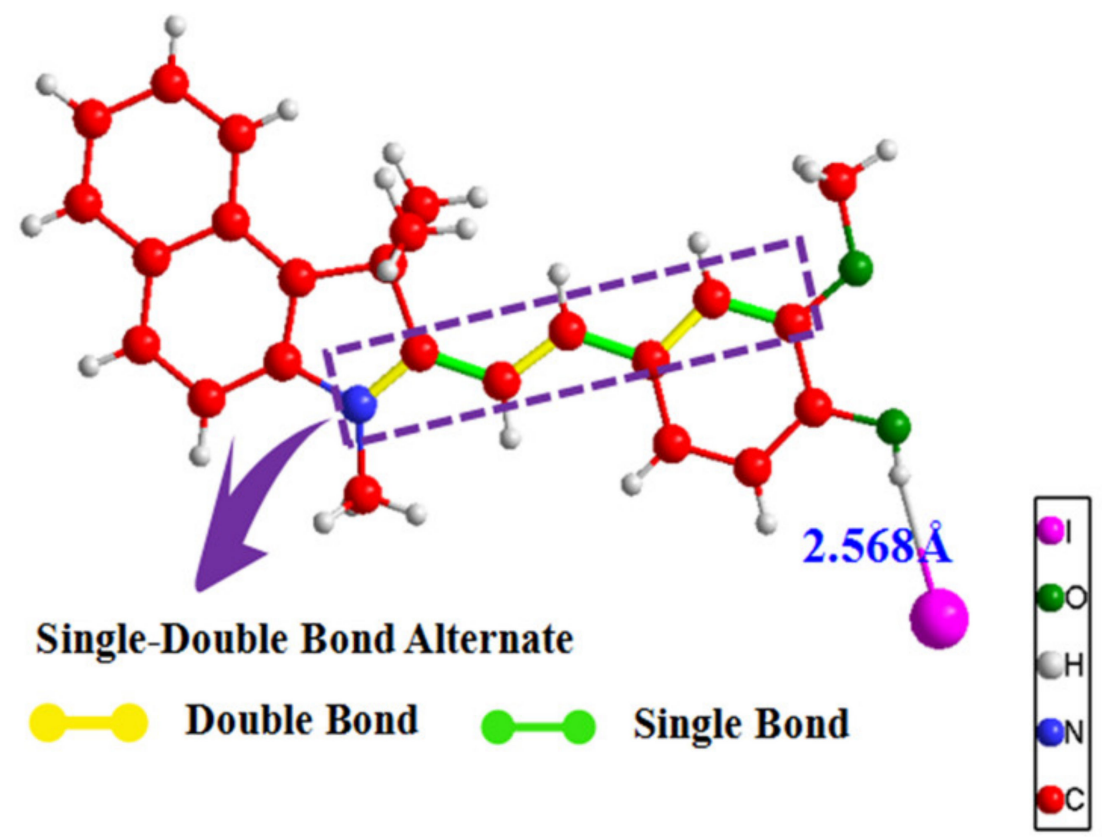

Figure 4. Schematic diagram of 1-TB single molecular structure.

\section{Conclusions}

In summary, we have synthesized two organic second-order nonlinear optical salts 1-TB and 2-TB containing benzo[e]indol cations. The measurements of the 1-TB and 2-TB powders from the methanol/acetonitrile $(1: 1 \mathrm{vol} / \mathrm{vol})$ show that both possess acentric core crystal structures. The SHG of the 1-TB and 2-TB powders are 0.76 and 0.58 times that of DAST, respectively, under the irradiation of $1064 \mathrm{~nm}$ laser. Among them, 1-TB has grown to a large-sized $\left(8.0 \times 3.0 \times 1.0 \mathrm{~mm}^{3}\right)$ organic single crystal by a slow cooling method in the above-mentioned solvent, and a small amount of regular shaped crystals precipitated with a smooth surface and a uniform thickness. Therefore, the 1-TB with good optical orientation and high temperature resistance will have a wide range of potential applications.

Supplementary Materials: The following are available online at http://www.mdpi.com/2073-4352/10/4/242/ s1. Figure S1: Thermal gravimetric analysis (TGA, left) and differential scanning calorimetry (DSC, right) thermodiagrams of the DAST, DSTMS, $1-\mathrm{TB}$ and 2-TB at a scanning rate of $10^{\circ} \mathrm{C} / \mathrm{min}$. Figure S2: Powder X-ray diffraction patterns for recrystallized 1-TB and 2-TB; Checkcif file.

Author Contributions: Conceptualization, Z.Y. and H.C.; methodology, X.Y.; validation, W.Z. and S.S.; formal analysis, D.W.; investigation, W.H.; resources, M.H.; writing —original draft preparation, J.W., L.P., R.L. All authors have read and agreed to the published version of the manuscript.

Funding: The financial support from National Natural Science Foundation of China (Grant no. 51673023, no. 51773017, no, 51373024), the State Key Laboratory for Advanced Metals and Materials (No. 2018Z-06) and the Fundamental Research Funds for the Central Universities (Grant No. FRF-DF-19-001).

Conflicts of Interest: The authors declare no conflicts of interest.

\section{References}

1. Czarske, J.; Zhang, S.; Sampson, D.; Wang, W.; Liao, Y. International Symposium on Optoelectronic Technology and Application 2014: Laser and Optical Measurement Technology; and Fiber Optic Sensors; SPIE-International Society for Optics and Photonics: Bellingham, WA, USA, 2014; Volume 19, pp. 514-522.

2. Dalton, L.R.; Sullivan, P.A.; Bale, D.H. Electric Field poled organic electro-optic materials: State of the art and future prospects. Chem. Rev. 2010, 110, 25-55. [CrossRef] [PubMed] 
3. Ferguson, B.; Zhang, X.-C. Materials for terahertz science and technology. Nat. Mater. 2002, 1, $26-33$. [CrossRef] [PubMed]

4. Federici, J.F.; Schulkin, B.; Huang, F.; Gary, D.; Barat, R.; Oliveira, F.; Zimdars, D. THz imaging and sensing for security applications-Explosives, weapons and drugs. Semicond. Sci. Technol. 2005, 20, S266-S280. [CrossRef]

5. Yang, X.; Zhao, X.; Yang, K.; Liu, Y.; Liu, Y.; Fu, W.; Luo, Y. Biomedical applications of terahertz spectroscopy and imaging. Trends Biotechnol. 2016, 34, 810-824. [CrossRef] [PubMed]

6. Gulbahar, B. Theoretical analysis of magneto-inductive $\mathrm{THz}$ wireless communications and power transfer with multi-layer graphene nano-coils. IEEE Trans. Inf. Technol. B 2017, 3, 60-70. [CrossRef]

7. Lin, W.H.; Wu, C.J.; Yang, T.J.; Chang, S.J. Terahertz intrinsic and effective surface impedances of high-temperature superconducting thin films. J. Electromagn. Wave 2010, 24, 2589-2603. [CrossRef]

8. Lee, S.-C.; Kang, B.J.; Lee, J.-A.; Lee, S.-H.; Jazbinšek, M.; Yoon, W.; Yun, H.; Rotermund, F.; Kwon, O.-P. Single crystals based on hydrogen-bonding mediated cation-anion assembly with extremely large optical nonlinearity and their application for intense THz wave generation. Adv. Opt. Mater. 2018, 6, 1701258. [CrossRef]

9. Song, N.-W.; Kang, T.I.; Jeoung, S.C.; Jeon, S.J.; Cho, B.R.; Kim, D. Improved method for measuring the first-order hyperpolarizability of organic NLO materials in solution by using the hyper-Rayleigh scattering technique. Chem. Phys. Lett. 1996, 261, 307-312. [CrossRef]

10. Marder, S.R.; Perry, J.W.; Schaefer, W.P. Synthesis of organic salts with large second-order optical nonlinearities. Science 1989, 245, 626. [CrossRef]

11. Mutter, L.; Brunner, F.D.; Yang, Z.; Jazbinšek, M.; Günter, P. Linear and nonlinear optical properties of the organic crystal DSTMS. Josa B 2007, 24, 2556-2561. [CrossRef]

12. Kwon, S.J.; Jazbinsek, M.; Kwon, O.; Günter, P. Crystal growth and morphology control of OH1 organic electrooptic crystals. Cryst. Growth Des. 2010, 10, 1552-1558. [CrossRef]

13. Suizu, K.; Miyamoto, K.; Yamashita, T.; Ito, H. High-power terahertz-wave generation using DAST crystal and detection using mid-infrared powermeter. Opt. Lett. 2007, 32, 2885-2887. [CrossRef] [PubMed]

14. Jazbinsek, M.; Ruiz, B.; Medrano, C.; Gunter, P. Broadband THz-wave generation with organic crystals OHI and DSTMS. In Proceedings of the Conference on Lasers \& Electro-Optics Europe \& International Quantum Electronics Conference CLEO EUROPE/IQEC IEEE, Munich, Germany, 12-16 May 2013.

15. Wu, B.; Cao, L.; Zhang, Z.; Fu, Q.; Xiong, Y. Terahertz electro-optic sampling in thick znte crystals below the reststrahlen band with a broadband femtosecond laser. IEEE Sci. Technol. 2018, 99, 1-7. [CrossRef]

16. Uchida, H.; Oota, K.; Okimura, K.; Kawase, K.; Takeya, K. Single-cycle terahertz pulse generation from OH1 crystal via cherenkov phase matching. J. Infrared Millim. Terahertz Waves 2018, 39, 1-5. [CrossRef]

17. Kim, J.; Lee, S.H.; Lee, S.C.; Jazbinsek, M.; Miyamoto, K.; Omatsu, T.; Lee, Y.S.; Kwon, O. Terahertz phonon modes of highly efficient electro-optic phenyltriene OH1 crystals. J. Phys. Chem. C 2016, 120, 24360-24369. [CrossRef]

18. Lee, S.-H.; Kang, B.-J.; Kim, J.-S.; Yoo, B.-W.; Jeong, J.-H.; Lee, K.-H.; Jazbinsek, M.; Kim, J.W.; Yun, H.; $\mathrm{Kim}$, J.; et al. New acentric core structure for organic electrooptic crystals optimal for efficient optical-to- $\mathrm{THz}$ conversion. Adv. Opt. Mater. 2015, 3, 756-762. [CrossRef]

19. Kang, B.J.; Baek, I.H.; Lee, S.H.; Kim, W.T.; Lee, S.J.; Jeong, Y.U.; Kwon, O.P.; Rotermund, F. Highly nonlinear organic crystal OHQ-T for efficient ultra-broadband terahertz wave generation beyond $10 \mathrm{THz}$. Opt. Express 2016, 24, 11054-11061. [CrossRef]

20. Kim, P.-J.; Jeong, J.-H.; Jazbinsek, M.; Choi, S.-B.; Baek, I.-H.; Kim, J.-T.; Rotermund, F.; Yun, H.; Lee, Y.S.; Günter, P.; et al. Highly efficient organic THz generator pumped at near-infrared: Quinolinium single crystals. Adv. Funct. Mater. 2012, 22, 200-209. [CrossRef]

21. Lee, S.H.; Lu, J.; Lee, S.J.; Han, J.H.; Jeong, C.U.; Lee, S.C.; Li, X.; Jazbinsek, M.; Yoon, W.; Yun, H.; et al. Benzothiazolium single crystals: A new class of nonlinear optical crystals with efficient $\mathrm{THz}$ wave generation. Adv. Mater. 2017, 29, 1701748. [CrossRef]

22. Lee, S.H.; Lee, S.J.; Jazbinsek, M.; Kang, B.J.; Rotermund, F.; Kwon, O.P. Electro-optic crystals grown in confined geometry with optimal crystal characteristics for THz photonic applications. CrystEngComm 2016, 18, 7311-7318. [CrossRef] 
23. Yang, Z.; Mutter, L.; Stillhart, M.; Ruiz, B.; Aravazhi, S.; Jazbinsek, M.; Schneider, A.; Gramlich, V.; Günter, P. Large-size bulk and thin-film stilbazolium-salt single crystals for nonlinear optics and THz generation. Adv. Funct. Mater. 2007, 17, 2018-2023. [CrossRef]

24. Li, X.; Yue, Y.; Wen, Y.; Yin, C.; Huo, F. Hemicyanine based fluorimetric and colorimetric $\mathrm{pH}$ probe and its application in bioimaging. Dye. Pigm. 2016, 134, 291-296. [CrossRef]

25. Hu, Z.; Sun, Z.; Sun, H. Design of zinc porphyrin-perylene diimide donor-bridge-acceptor chromophores for large second-order nonlinear optical response: A theoretical exploration. Int. J. Quantum Chem. 2017, 118, e25536. [CrossRef]

26. Li, M.; Li, Y.; Zhang, H.; Wang, S.; Ao, Y.; Cui, Z. Molecular engineering of organic chromophores and polymers for enhanced bulk second-order optical nonlinearity. J. Mater. Chem. C 2017, 5, 4111-4122. [CrossRef]

27. Brunner, F.D.; Kwon, O.P.; Kwon, S.J.; Jazbinsek, M.; Schneider, A.; Günter, P. A hydrogen-bonded organic nonlinear optical crystal for high-efficiency terahertz generation and detection. Opt. Express 2008, 16, 16496-16508. [CrossRef]

28. Yang, Z.; Ruiz, B.; Aravazhi, S.; Stillhart, M.; Jazbinsek, M.; Gramlich, V.; Günter, P. Molecular engineering of stilbazolium derivatives for second-order nonlinear optics. Chem. Mater. 2007, 19, 3512-3518. [CrossRef]

29. Goebel, T.; Prots, Y.U.; Haarmann, F. Refinement of the crystal structure of tetrasodium tetrasilicide, $\mathrm{Na}_{4} \mathrm{Si}_{4}$. Z. Für Krist. New Cryst. Struct. 2008, 223, 187-188. [CrossRef]

30. Chen, H.; Ma, Q.; Zhou, Y.; Yang, Z.; Jazbinsek, M.; Bian, Y.; Ye, N.; Wang, D.; Cao, H.; He, W. Engineering of organic chromophores with large second-order optical nonlinearity and superior crystal growth ability. Cryst. Growth Des. 2015, 15, 5560-5567. [CrossRef]

31. Wu, J.; Peng, C.; Xiao, H.; Bo, S.; Qiu, L.; Zhen, Z.; Liu, X. Donor modification of nonlinear optical chromophores: Synthesis, characterization, and fine-tuning of chromophores' mobility and steric hindrance to achieve ultra large electro-optic coefficients in guest-host electro-optic materials. Dye. Pigm. 2014, 104, 15-23. [CrossRef]

32. Yang, Z.; Ping, L.J.; Liu, X.; Shang, S.F.; Wang, D.; Cao, H.; He, W.L. Organic Salt Optical Crystal Containing Benzoindole Group and Its Preparation Method and Application. (In Chinese). China Patent CN201810777919.X, 11 December 2018. 